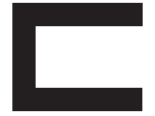

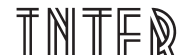

ER(ES

CIENTÍFICAS

EXATAS E TECNOLÓGICAS

ISSN IMPRESSO - 2359-4934

E- ISSN - 2359-4942

DOI - 10.17564/2359-4934.2016v2n2p9-18

\title{
ESTUDO DO USO DE BORRA OLEOSA NA MODIFICAÇÃO DE LIGANTE ASFÁLTICO DE PETRÓLEO PARA FINS DE PAVIMENTAÇ̃̃o
}

\section{RESUMO}

0 presente trabalho apresenta o comportamento reológico do cimento asfáltico de petróleo (CAP 50/70), no estado puro e modificado, quando do acréscimo de $20 \%$ de borra oleosa, visando seu uso em revestimentos de pavimentações. Com o objetivo de caracteriza-los e avaliar os efeitos sobre suas propriedades. Resultados obtidos com o uso do Reômetro de Cisalhamento Dinâmico (Dynamical Shear Rheometer DSR), em regime oscilatório. Obtendo o resultado de que a amostra pura é mais resistente e rígida a deformação, possuindo também melhores propriedades.

\section{PALAVRAS-CHAVE}

Reômetro de Cisalhamento Dinâmico. Borra Oleosa. CAP 50/70. Reologia. Pavimentação. 


\section{RESUMEN}

Este artículo presenta el comportamiento reológico de cemento asfáltico bituminoso (AC 50/70), crudo y modificado, cuando hay la adición de $20 \%$ de lodo aceitoso, con el objetivo de su uso en revestimientos de suelo. Con el fin de caracterizarlos y evaluar los efectos sobre sus propiedades. Los resultados obtenidos mediante el reómetro de corte dinámico (Dynamical Shear Rheometer - DSR) en régimen oscilatorio. Obteniendo el resultado de que la muestra pura es

\section{ABSTRACT}

This paper presents the rheological behavior of asphaltic oil cement (CAP 50/70), in pure and modified state, when there is the addition of $20 \%$ of oily sludge, aiming its use in floor coverings in order to characterize them and evaluate the effects on their properties. Results obtained using the Dynamic Shear Rheometer (Dynamical Shear Rheometer - DSR) in oscillatory regime. Obtaining the result that the pure sample is more resistant and rigid deformation, also having improved properties. más resistente a la deformación y más rígido y tiene también mejores propiedades.

\section{PALABRAS CLAVE}

Reómetro Dinámico de Cizalla. BORRA. AC 50/70. Reología. Pavimentación.

\section{KEYWORDS}

Rheometer Shear Dynamic. Oily sludge. CAP 50/70. Rheology. Paving. 


\section{INTRODUÇ̄̃̃O}

Os ligantes asfálticos devem atender a parâmetros associados às condições das quais os pavimentos serão submetidos (LIMA; SOARES, 2006). Nos pavimentos flexíveis o revestimento é uma mistura asfáltica, constituída de ligante asfáltico e agregados minerais, podendo conter algum tipo de aditivo (FARIAS ET AL., 2011).

0 estudo da modificação de ligantes asfálticos no Brasil foi iniciado a partir de 1960, testando ligantes modificados de revestimentos asfálticos em vários estados (AMARAL, 2000).

Nas últimas décadas a frequência de tráfego nos pavimentos teve grande crescimento, aumentando as tensões aplicadas por ele. Criando assim a necessidade do uso de novas tecnologias para avaliar e estudar as propriedades de materiais asfálticos, como por exemplo, os ligantes betuminosos, conhecendo o seu comportamento reológico e garantindo uma pavimentação com técnicas seguras e duráveis (LIMA; SOARES, 2006).

Os ligantes betuminosos possuem comportamento viscoelástico, ou seja, exibem comportamento elástico e viscoso. Quando há a aplicação de carregamento, se deformam, recuperando-se em parte (pelas propriedades elásticas que possuem) e a mantém em parte (devido às propriedades viscosas que também possui) (GONZÁLEZ ET AL., 2006; BARROS, 2012).

Devido a esse comportamento, o ensaio executado com o uso do Reômetro de Cisalhamento Dinâmico (Dynamical Shear Rheometer - DSR) analisa a capacidade de esses materiais resistirem a deformações permanentes e à fadiga.

Os ligantes asfálticos têm suas propriedades modificadas (físicas e químicas) com o uso de aditivos, sendo assim é necessário e importante o estudo químico e reológico, visando ter a ideia do futuro desempenho destes materiais quando da sua aplicação (MORRILHA, 2004).

O ensaio com o reômetro de cisalhamento dinâmico pode ser realizado com o ligante original ou não. Quantifica-se o módulo complexo ( $\left.G^{*}\right)$ e o ângulo de fase (), numa determinada temperatura e frequência, caracterizando o ligante como elástico ou viscoso (BARROS, 2012). Um modificador que pode ser utilizado é a Borra oleosa de petróleo.

A Borra é um resíduo oleoso obtido na exploração e produção de petróleo, no seu tratamento primário, é de difícil destinação e tratamento, sendo na maioria das vezes dispostos em tanques ou em aterros industriais. Seu impacto ambiental pode ser reduzido com o uso de tecnologias que reduzam a sua produção, ou por meio do seu reaproveitamento (reciclagem) (FARIAS ET AL., 2011).

Seu reuso torna-se vantajoso pelas seguintes razões: reutiliza-los reduz seu armazenamento, reduzindo também a demanda por espaço físico no uso de aterros, ou seja, um menor custo para a indústria petrolífera na disposição deste resíduo; além da redução de impactos ambientais, pois quando não destinados corretamente há o grande risco de contaminação do solo e das águas (superficiais e subterrâneas) devido a sua composição química (BUTT ET AL., 2008).

Utilizá-la na modificação de asfaltos é uma ideia que passou a ser estudada apenas recentemente, mas já se conhecem os benefícios, como a redução nos custos de manutenção de rodovias e uma maior resistência à abrasão, envelhecimento e oxidação (FARIAS ET AL., 2011).

Esse estudo tem por objetivo caracterizar e assim analisar o comportamento das propriedades reológicas do ligante asfáltico CAP 50/70 e compará-lo ao 
CAP 50/70 com 20\% de borra oleosa adicionada, estruturado da seguinte forma: a seção dois apresenta os materiais e método, além do procedimento experimental. Os resultados obtidos são apresentados na seção três e as considerações finais na seção quatro.

\section{MATERIAIS E MÉTODO}

\subsection{MATERIAIS UTILIZADOS}

Foram utilizados na produção deste estudo CAP 50/70, cedida pelo município de Aracaju por meio da Usina de Processamento de Asfalto da EMURB, borra oleosa cedida pela PETROBRAS Unidade de Negócio de Exploração e Produção de Sergipe e Alagoas (UN-SEAL).

\subsection{EQUIPAMENTO UTILIZADO}

Na execução do estudo foram realizados ensaios reológicos com amostras de CAP no estado puro e modificado, num DSR (Figura 1). O equipamento é constituído de uma geometria de placas paralelas, as amostras são inseridas entre elas e conduzidas a um regime oscilatório, examinando assim suas propriedades reológicas.

Figura 1 - Equipamento utilizado para o ensaio DSR, Reômetro de Cisalhamento Dinâmico

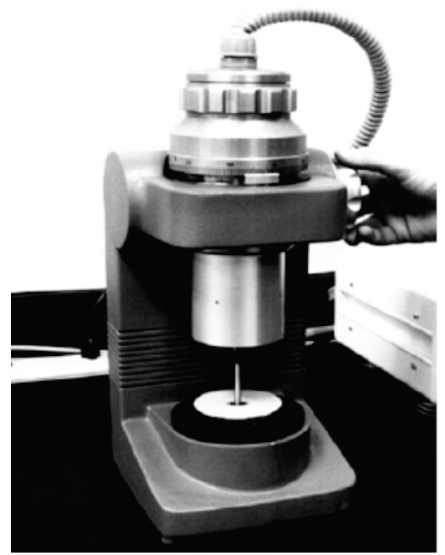

Fonte: Barros (2012).

\subsection{PROCEDIMENTO EXPERIMENTAL}

Os corpos de prova foram produzidos num molde (em silicone), cujas dimensões são as seguintes: 25 $\mathrm{mm}$ de diâmetro por $1 \mathrm{~mm}$ de espessura, em temperatura de $170^{\circ} \mathrm{C} \pm 5^{\circ} \mathrm{C}$. Os corpos de prova são analisados a uma temperatura de $60^{\circ} \mathrm{C}$, visando aferir como se comportam as suas propriedades reológicas.

Sendo as propriedades medidas (em razão da frequência angular):

- Módulos elásticos - G' (também chamados de módulos de armazenamento);

- Módulos viscosos - G” (módulos de perda);

- Módulos complexos - G*;

- Coeficiente de amortecimento - tan. (ס);

- Resistência ao acúmulo - $\left|G^{*}\right| / \operatorname{sen}(\delta)$;

- Rigidez ao acúmulo - $\left|G^{*}\right| \cdot \operatorname{sen}(\bar{\delta})$.

Mediu-se o módulo complexo de cisalhamento $\left(G^{*}\right)$ e o ângulo de fase ( $\left.\delta\right)$, onde o corpo de prova é submetido a tensões de cisalhamento oscilatórias, entre duas placas paralelas.

Pode-se relacionar o módulo complexo com a resistência do material e com o ângulo de fase se obtém informações sobre a razão entre a resposta elástica e viscosa durante o processo de cisalhamento.

0 módulo complexo (G*) e o ângulo de fase (ס) são definidos de acordo com a Equação 1:

$$
G^{*}=\frac{\tau_{\text {máx }}}{\gamma_{\text {máx }}} \text { e } \delta=\omega .(\Delta t)
$$


Onde:

$\mathrm{G}^{*}$ - módulo complexo de cisalhamento;

$\delta$ - ângulo de fase;

$T_{\text {máx }}$ - máxima tensão de cisalhamento aplicada;

$V_{\text {máx }}$ - máxima deformação, que ocorre após a ten-

são de cisalhamento;

$\omega$ - frequência angular;

$\Delta \mathrm{t}$ - tempo de defasagem.

A Figura 2 mostra um esquema de valores de $G^{*} \mathrm{e}$ $\delta$, no qual a primeira parte representa a tensão aplicada e a segunda a deformação resultante, $\Delta$ t representa um atraso na deformação obtida, que ao ser multiplicado pela frequência angular obtém-se o ângulo de fase.

Figura 2 - Esboço de gráfico do comportamento de fluido viscoelástico Comportamento viscoelástico

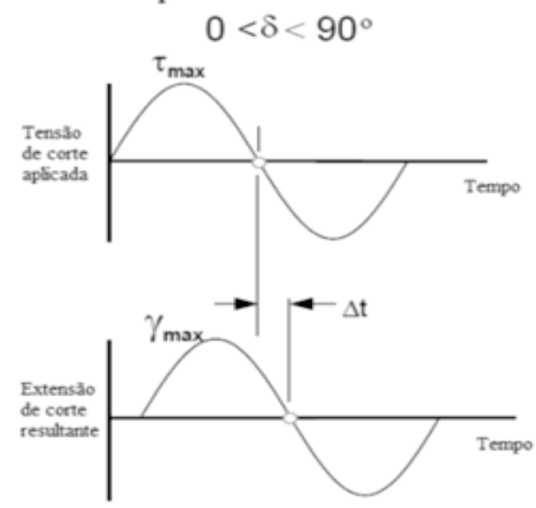

Fonte: Motta e outros autores (1996).

A partir destes dados podem-se obter outros parâmetros e assim realizar uma análise das propriedades:

Módulo de armazenamento (G') associado à contribuição elástica do material:

$$
\mathrm{G}^{\prime}=\frac{\tau_{0}}{\gamma_{0}} \cos (\delta)
$$

Módulo de perda (G") associado à contribuição viscosa do material:

$$
\mathrm{G}^{\prime \prime}=\frac{\tau_{0}}{\gamma_{0}} \operatorname{sen}(\delta)
$$

A magnitude do módulo complexo é obtida por:

$$
\left|\mathrm{G}^{*}\right|=\sqrt{\mathrm{G}^{\prime 2}+\mathrm{G}^{\prime 2}}
$$

O controle da resistência ao acúmulo e da rigidez ao acúmulo são obtidos por

$G^{*} / \operatorname{sen}(\delta)$ e por $G^{*} \cdot \operatorname{sen}(\delta)$, respectivamente (BARROS, 2012).

Outra representação executada neste estudo é a curva de Black, constituída plotando-se o módulo complexo $\left(\left|G^{*}\right|\right)$ em função do ângulo de fase $(\delta)$ (BRINGEL ET AL., 2008).

A análise reológica foi executada para CAP 50/70, comparada ao CAP 50/70 modificado com o acréscimo de $20 \%$ de borra, na temperatura de $60^{\circ} \mathrm{C}$, em regime oscilatório e usando os dados obtidos foram produzidos os seguintes gráficos (para a comparação das amostras): Módulo Complexo $\left|G^{*}\right|$ x Frequência angular ( $\omega)$; Módulo elástico (G'), Módulo viscoso (G”) $x$ Frequência angular $(\omega)$; ângulo de fase $(\delta) \times$ Frequência angular ( $\omega)$; tan $(\delta) \times$ Frequência angular $(\omega)$; $\left|G^{*}\right| / \operatorname{sen}(\delta) \times$ Frequência angular $(\omega) ;\left|G^{*}\right| \operatorname{sen}(\delta) \times$ Frequência angular ( $\omega)$; Viscosidade complexa $\left(n^{*}\right) \times$ Frequência angular $(\omega)$ e a Compliança Complexa $\left|J^{*}\right|$ $x$ Frequência angular ( $\omega)$.

\section{RESULTADOS}

$\mathrm{Na}$ análise do módulo complexo $\left(\mathrm{G}^{*}\right)$ observou-se que, para a amostra de CAP 50/70 puro e para o CAP 
com $20 \%$ de Borra, seu valor aumentou em frequências angulares (w) maiores (Figura 3). Na comparação entre as amostras têm-se valores maiores de $G^{*}$ que o CAP puro para a mesma frequência angular, o que demostra que a amostra pura é mais resistente a deformações aplicadas que a amostra com adição de 20 $\%$ de Borra para esta temperatura, portanto para este parâmetro a borra não seria indicada, buscando melhorias na resistência de um pavimento.

Figura 3 - Comportamento do módulo complexo em função da frequência angular para o CAP 50/70 puro e modificado com adição de $20 \%$ de Borra a $60^{\circ} \mathrm{C}$

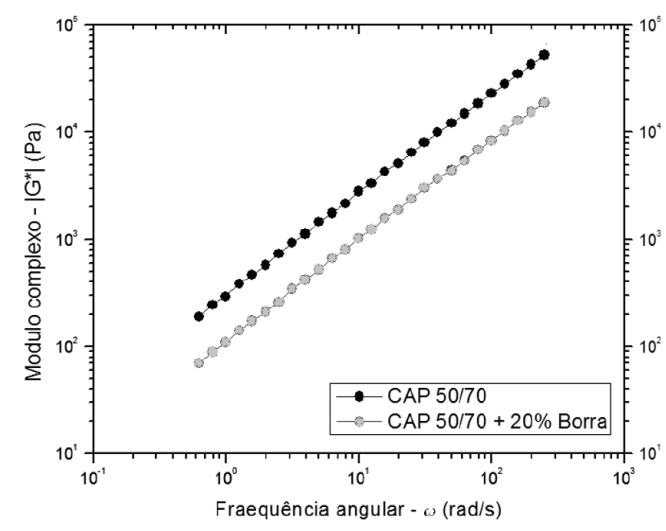

Fonte: Dados da pesquisa.

Na Figura 4 pode-se ver o comportamento do módulo elástico (G') e do módulo viscoso (G”) em função da frequência angular. O CAP puro possui resposta elástica e viscosa superior a amostra modificada com $20 \%$ de Borra (a resposta elástica ocorre a partir de uma frequência angular de aproximadamente $2,5 \mathrm{rad} / \mathrm{s}$ ). Os valores do módulo viscoso encontrados foram maiores que os do módulo elástico para o ligante puro.

Já para o ligante modificado com Borra, que apresentou valores do módulo viscoso, consideravelmente maiores do que os do módulo elástico, há também valores de módulo complexo menores do que o ligante puro. Observa-se que a resposta viscosa (G") excede a resposta elástica (G') nas duas amostras, logo a modificação indica uma possível redução na resistência do ligante a deformações que sejam aplicadas nesta temperatura.

Figura 4 - Comportamento do módulo elástico (G') e do módulo viscoso (G") em função da frequência para o CAP 50/70 puro e modificado com adição de $20 \%$ de Borra a $60^{\circ} \mathrm{C}$

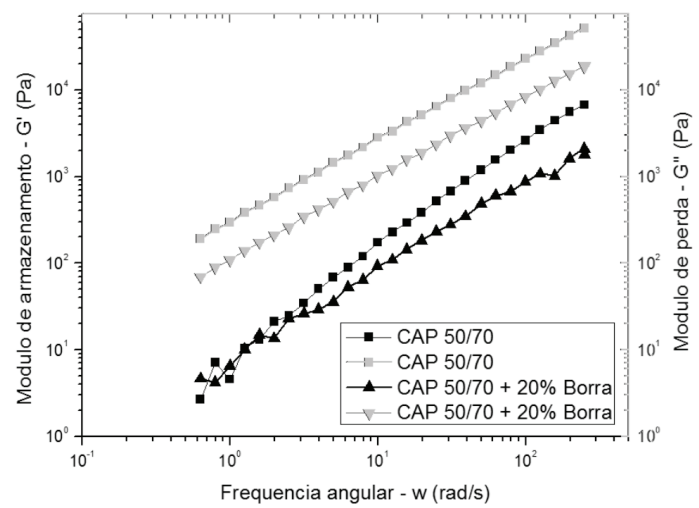

Fonte: Dados da pesquisa.

O gráfico da Figura 5 representa o comportamento do ângulo de fase ( $\delta$ ) em função da frequência angular. Nele os valores de ângulo de fase são similares para a amostra do CAP 50/70 puro e para o modificado com $20 \%$ de borra, portanto para este parâmetro não foi possível analisar mudanças em seu comportamento.

Figura 5 - Comportamento do ângulo de fase em função da frequência angular para o CAP $50 / 70$ puro e modificado com adição de $20 \%$ de Borra a $60^{\circ} \mathrm{C}$

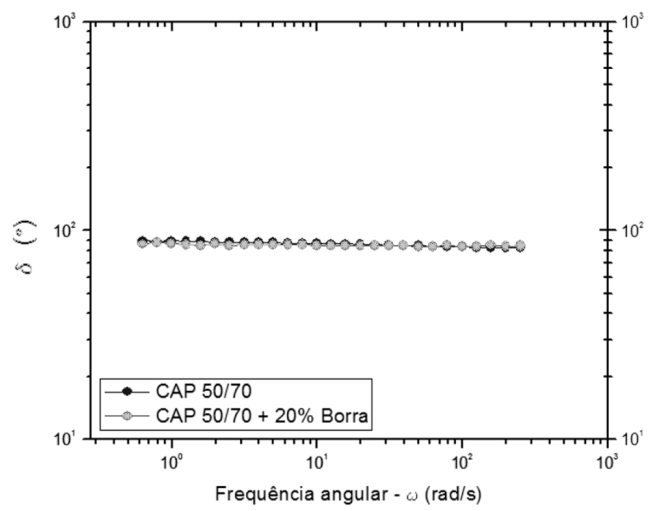

Fonte: Dados da pesquisa. 
Na Figura 6 observa-se o comportamento do fator de amortecimento ( $\tan \delta$ ) em função da frequência angular, onde se percebe que com a adição da Borra os valores de $\tan \delta$ foram menores do que para o ligante puro até uma frequência de aproximadamente $70 \mathrm{rad} / \mathrm{s}$, o que mostra que há um aumento de elasticidade do CAP com a adição de $20 \%$ de Borra, a partir deste valor o fator de amortecimento foi maior para do ligante modificado com Borra do que para o ligante puro, demonstrando que há um limite para este aumento de elasticidade. Observa-se também que a Borra adicionada torna a curva mais plana durante a faixa de frequência estudada.

Figura 6 - Comportamento do coeficiente de amortecimento em função da frequência angular para o CAP 50/70 puro e modificado com adição de $20 \%$ de Borra a $60^{\circ} \mathrm{C}$

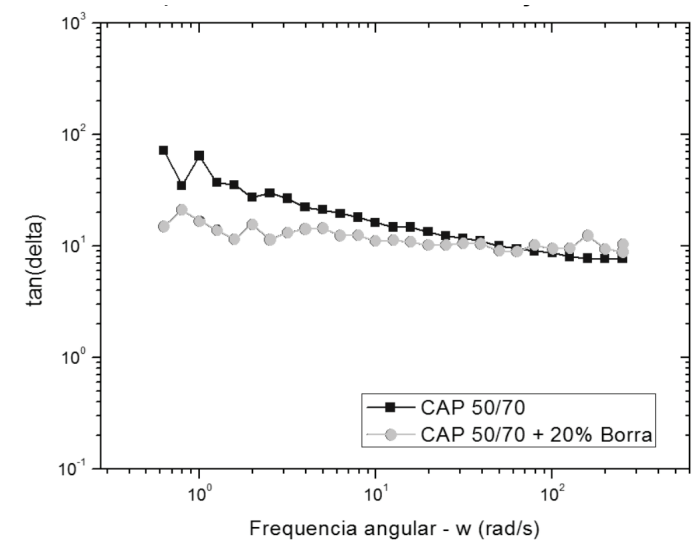

Fonte: Dados da pesquisa.

A Figura 7 mostra redução da resistência ao acúmulo de deformação permanente $\left(G^{*} /\right.$ sen $\left.\delta\right)$ com a adição de Borra. A Figura 8 mostra o comportamento da rigidez ao acúmulo da deformação permanente em relação à frequência angular. Valores menores de resistência ao acúmulo de deformação permanente e da rigidez ao acúmulo de deformação permanente no CAP modificado com Borra indica uma piora na resistência a deformação permanente, o que pode significar um pior desempenho em um pavimento.
Figura 7 - Comportamento da resistência ao acúmulo da deformação permanente em função da frequência angular para o CAP 50/70 puro e modificado com adição de $20 \%$ de Borra a $60^{\circ} \mathrm{C}$

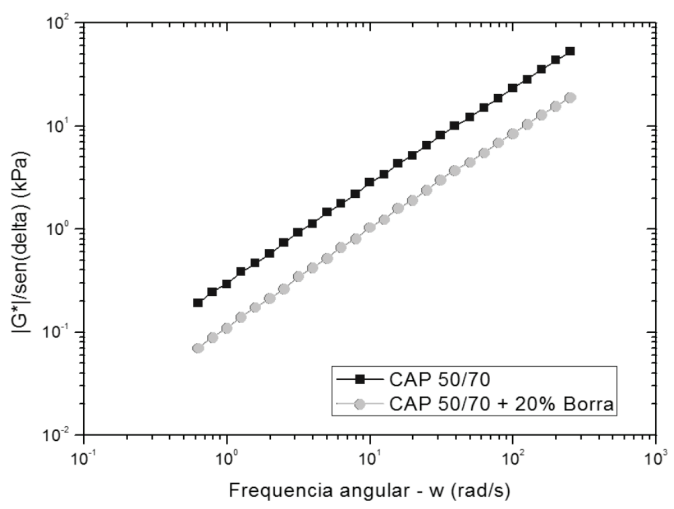

Fonte: Dados da pesquisa.

Figura 8 - Comportamento da rigidez ao acúmulo da deformação permanente em função da frequência angular para o CAP 50/70 puro e modificado com adição de $20 \%$ de Borra a $60^{\circ} \mathrm{C}$

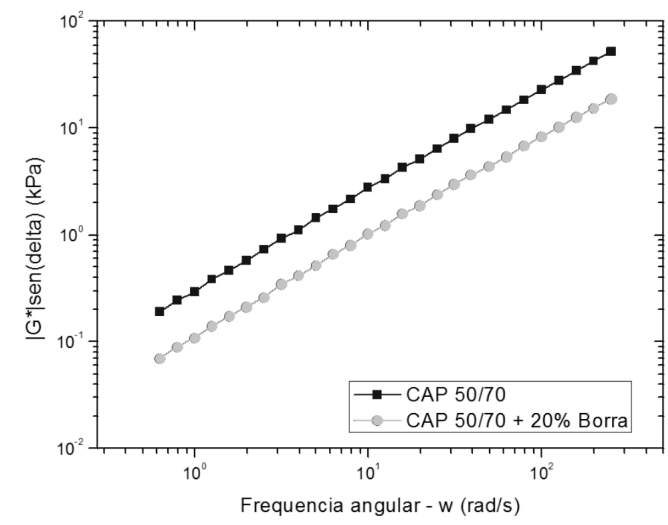

Fonte: Dados da pesquisa.

No gráfico da Figura 9 há a correlação da viscosidade complexa com a frequência angular. O CAP modificado com Borra apresenta valores de viscosidade menores do que o CAP puro. Para o CAP 50/70 puro há um desempenho ligeiramente pseudoplástico, representado pelo decréscimo dos valores de viscosidade em frequências mais elevadas, o mesmo ocorre para o CAP com $20 \%$ de Borra. 
Figura 9 - Comportamento da viscosidade complexa em relação à frequência angular para o CAP 50/70 puro e modificado com adição de $20 \%$ de Borra a $60^{\circ} \mathrm{C}$

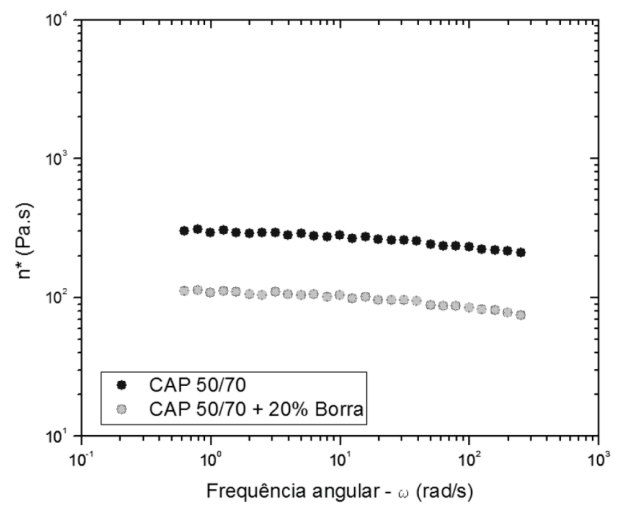

Fonte: Dados da pesquisa.

Por meio dos valores de compliança é possível saber se um material é mais elástico ou mais viscoso. Na Figura 10 é possível observar o gráfico que mostra os valores da compliança complexa $\left(J^{*}\right)$ em relação à frequência angular (w). Nota-se que os valores da compliança do CAP 50/70 puro foram menores que os valores do CAP 50/70 modificado com $20 \%$ de Borra. 0 que sugere que o CAP modificado oferece menor capacidade de deformação quando comparada a amostra pura, e também uma redução em sua resposta elástica.

Figura 10 - Comportamento da compliança complexa em relação a frequência angular para o CAP 50/70 puro e modificado com adição de $20 \%$ de Borra a $60^{\circ} \mathrm{C}$.

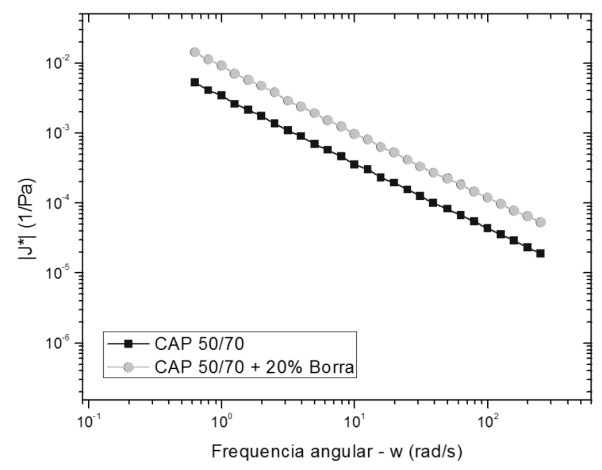

Fonte: Dados da pesquisa.

\section{CONSIDERACÕ̃ES FINAIS}

A partir do estudo reológico do ligante asfáltico (CAP 50/70), partindo do ensaio com o reômetro de cisalhamento dinâmico (DSR), foi observado que suas características (propriedades) foram alteradas na amostra de ligante modificado com $20 \%$ de borra.

A amostra pura se mostrou mais resistente e mais rígida à deformação, suas respostas, elástica e viscosa, também são superiores aos resultados obtidos para a amostra com adição de borra, mas sendo a resposta elástica superior a viscosa para as duas amostras. Para a amostra modificada também são menores a resistência e a rigidez à deformação permanente.

É visto que o estudo realizado evidencia que o CAP 50/70, ou seja, a amostra pura possui melhores propriedades que o ligante asfáltico modificado, ou seja, com os resultados obtidos, a adição de $20 \%$ de borra oleosa de petróleo pode não ser apropriada completamente para o uso em aplicações de revestimentos asfálticos, mas pode ser adequada para outros usos, como modificador de ligantes asfálticos, dando assim uma melhor destinação ao material, de uma perspectiva ambiental (evitando a contaminação do solo e da água quando não destinados corretamente) e socioeconômica.

Apesar disso, os resultados apresentados atendem particularmente a proporção estudada, se fazendo necessário, em futuras análises, verificar o comportamento reológico em outras proporções.

\section{REFERÊNCIAS}

\section{AMARAL, S.C. Estudo de misturas asfálticas densas com agregados do Estado do Pará utilizando asfalto convencional (CAP-40) e asfalto modificado com polímero SBS (Betuflex B 65/60). 2000. 218f.}

Dissertação (Mestrado em Engenharia Civil) Universidade de São Paulo, São Carlos, 2000. 
BARROS, E.S.S. Comportamento dos betumes em função da temperatura. 2012. 190f. Dissertação (Mestrado em Engenharia Civil) - Universidade do Porto, Porto, 2012.

BUTT, T.E.; LOCKLEY, E.; ODUYEMI, K.O.K. Risk assessment of landfill disposal sites - State of the art. Waste Management Journal, n.28, 2008. p.952-964.

BRINGEL, R.M. et al. Análise dos parâmetros reológicos através das curvas mestras do ligante asfáltico modificado por SBS e EVA. In: $19^{\circ}$ ENCONTRO DE ASFALTO - Instituto Brasileiro de Petróleo, Gás e Biocombustíveis IBP, Anais do $19^{\circ}$ Encontro de Asfalto, Rio de Janeiro, 2008.

FARIAS, R.S. et al. Uso de borra oleosa e borracha de pneus inservíveis na modificação de ligante asfáltico de petróleo CAP 50/70. In: $11^{\circ}$ CONGRESSO BRASILEIRO DE POLIIMEROS, Anais do $\mathbf{1 1}^{\circ}$ Congresso Brasileiro de Polímeros. Campos do Jordão, 2011.

GONZÁLES, O.; MUÑOZ, M.E.; SANTAMARÍA, A. Bitumen/polyethylene blends: using m-LLDPEs to improve stability and viscoelastic properties. Rheologica Acta Journal, v.45, 2006. p.603-610.

LIMA, C.S.; SOARES, J.B. Caracterização e desenvolvimento de ligantes asfálticos modificados com borracha de pneu e aditivos. In: XX CONGRESSO DE PESQUISA E ENSINO EM TRANSPORTES - ANPET, Anais do XX ANPET. Brasília, Distrito Federal, 2006.

MORRILHA, A.J. Estudo sobre a ação de modificadores no envelhecimento nos ligantes asfálticos e nas propriedades mecânicas e de fadiga das misturas asfálticas. 2004. $165 f$. Dissertação (Mestrado em Engenharia Civil) - Universidade Federal de Santa Catarina, Florianópolis, 2004.

MOTTA, L M.G.; SÁ, M.F.P.; OLIVEIRA, P.M.F.; SOUZA, A.M. O ensaio de Creep Estático e dinâmico na avaliação das misturas asfálticas. In: 30ª REUNIÃO ANUAL DE PAVIMENTAÇÃO, p.115-135, Anais da 30 ${ }^{\text {a }}$ Reunião Anual de Pavimentação. Salvador, 1996. 
1. Mestrando de Engenharia Civil pela Universidade Federal de Sergipe; Graduado em Engenharia Civil pela Universidade Federal de Sergipe. E-mail: lucas.civil@yahoo.com.br

Aceito em: 2 de Abril de 2016

2. Doutora, Professora e Pesquisadora da Universidade Federal de Sergipe Departamento de Engenharia Química. E-mail: giselia8j@gmail.com 